Faculdade de Ciências Econômicas UFRGS
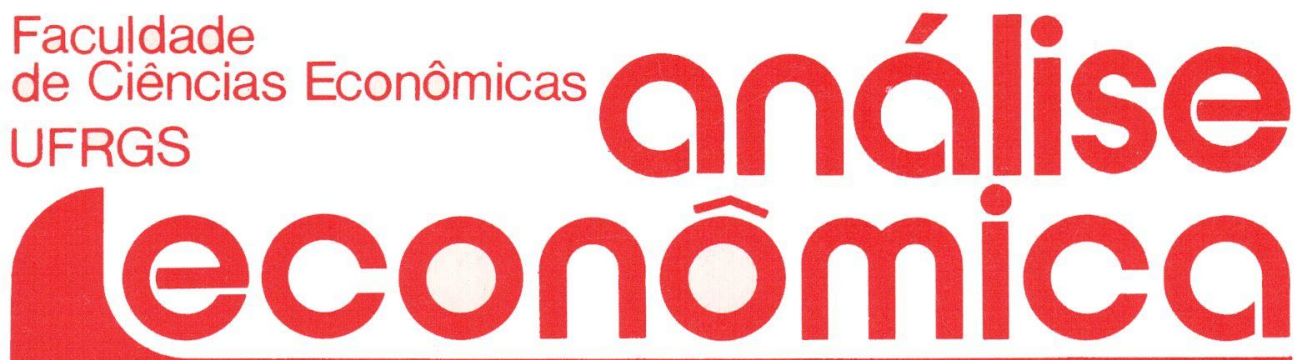

- apResentaÇ̃o à "ANálise simples da MAXIMIZAÇÂO DO BEM-ESTAR" DE FRANCIS BATOR

João Rogério Sanson

- UMA ANÁlise SIMPLES da MAXIMIZAÇÃo do BEM-ESTAR

Francis M. Bator

- O Regime de câmbio flutuante numa ETAPA DE TRANSICÃO

Francisco Eduardo Pires de Souza

- AgREgAdos monetÁRIOS, NIVEL DE RENDDA NOMINAL, TAXA DE INFLAÇÃO: UMA ANÁLISE DA CAUSALIDADE NO BRASIL, 1972 A 1987

Divanildo Triches

- A EXPlosão de CONSUMO do CRUzAdo Marcelo Cortes Neri

- METOdologia de PLANEJAMENTO do SETOR ELÉTRICO: QUESTŐES DOS ANOS 90

João Lizarolo de Araújo

Adilson de Oliveira

- CONCENTRAÇÃo INDUSTRIAL NO BRASIL SEGUNDO OS CENSOS, 1907-1980

Olimpio J. de Arrouxelas Galvão

- O VAlor, A RIQUEza e A TEORIA DE SMITH Reinaldo A. Carcanholo

- O "ESTADO ESTACIONÁRIO" e A ECONOMIa CLÁSSICA

Gentil Corazza

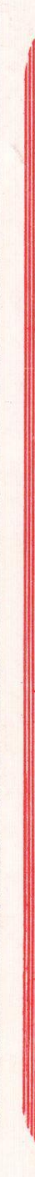
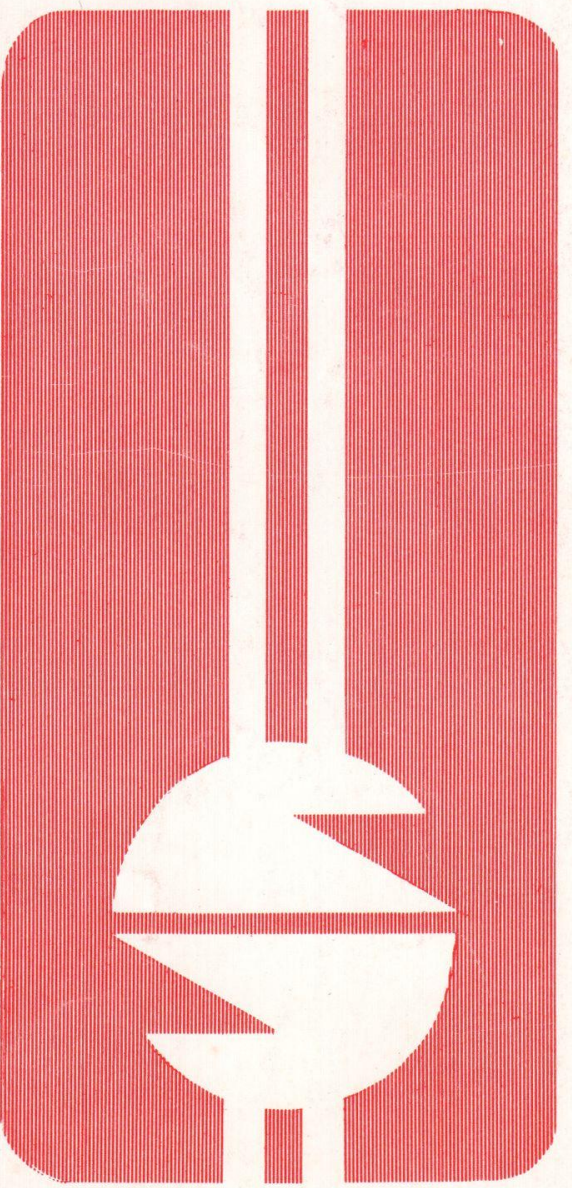
UNIVERSIDADE FEDERAL DO RIO GRANDE DO SUL

Reitor: Prof Tuiskon Dick

FACULDADE DE CIÊNCIAS ECONÔMICAS

Diretora: Prof ${ }^{\text {a }}$ Yeda Rorato Crusius

CENTRO DE ESTUDOS E PESQUISAS ECONÔMICAS

Diretor: Reinaldo Ignacio Adams

DEPARTAMENTO DE CIÊNCIAS ECONÔMICAS

Chefe: Prof. Pedro Cezar Dutra Fonseca

CURSO DE PÓS-GRADUAÇĀO EM ECONÔMIA

Coordenador: Prof. Nali de Jesus de Souza

CURSO DE PÓS-GRADUAÇĀO EM ECONOMIA RURAL

Coordenador: Prof. Atos Freitas Grawunder

CONSELHO EDITORIAL: Achyles Barcelos da Costa, Aray Miguel Feldens, Atos Freitas Grawunder, Carlos Augusto Crusius, Ernani Hickmann, João Rogério Sanson, Juvir Luiz Mattuella, Maria Imilda da Costa e Silva, Nali de Jesus de Souza, Nuno Renan Lopes de Figueiredo Pinto, Otilia Beatriz Kroeff Carrion, Otto Guilherme Konzen, Paulo Alexandre Spohr, Pedro Cezar Dutra Fonseca, Reinaldo Ignacio Adams, Roberto Camps Moraes, Valter José Stülp, Yeda Rorato Crusius, David Garlow (Wharton Econometrics Forecasts Association, E.U.A.), Edgar Augusto Lanzer (UFSC), Eleutério F. S. Prado (USP), Fernando Holanda Barbosa (FGV/RJ), Gustavo Franco (PUC/RJ), Joaquim Pinto de Andrade (UNB), Juan H. Moldau (USP), Werner Baer (Univ. de Illinois, E.U.A.)

COMISSÃO EDITORIAL: Atos Freitas Grawunder, Pedro Cezar Dutra Fonseca, Reinaldo Ignacio Adams e Roberto Camps Moraes.

EDITOR: Nali de Jesus de Souza

SECRETARIA: Maria Ivone de Mello (normalização), Vanete Ricacheski (revisão de textos), Zélide Bregalda (Secretária)

FUNDADOR: Prof. Antônio Carlos Santos Rosa

Os materiais publicados na revista Análise Econômica são de exclusiva responsabilidade dos autores. $\dot{E}$ permitida a reprodução total ou parcial dos trabalhos, desde que seja citada a fonte.

Aceita-se permuta com revista congêneres. Aceitam-se, também, livros para divulgação, elaboração de resenhas ou recensões.

Toda correspondência, material para publicaçāo (vide normas na $3^{\mathrm{a}}$ capa), assinaturas e permutas devem ser dirigidos ao seguinte destinatário:

PROF. NALI DE JESUS DE SOUZA

Revista Análise Econômica

Av. João Pessoa, 52

90.040 - PORTO ALEGRE (RS), BRASIL

Telefones: (0512) 28.1633; 24.6022; 26.0012 - Ramals 3440 e 3507

FAX: (0512) 25.5253 


\title{
METODOLOGIA DE PLANEJAMENTO DO SETOR ELÉTRICO: QUESTÕES DOS ANOS 90
}

\author{
João Lizarolo de Araújo* \\ Adilson de Oliveira*
}

\begin{abstract}
SINOPSE
Os métodos de planejamento hoje em uso pelo setor elétrico brasileiro foram formados ao longo dos anos sessenta e setenta, e mostraram-se perfeitamente adequados aos problemas e ao contexto económico-industrial da época. A crise da dívida e a ascensão do neoliberalismo nos anos oitenta, entretanto, vieram modificar de maneira radical aquele contexto. Por outro lado, a crescente preocupação com o meio ambiente e com o uso eficiente da energia trouxe novos problemas para o setor. E nossa tese que as profundas mudanças ocorridas no elenco de problemas e no contexto do planejamento exigem modificações de mesma ordem nos métodos de planejamento. Neste trabalho, discutimos os problemas e o contexto provável nos anos noventa, e as modificações metòdológicas que seriam necessárias.
\end{abstract}

\section{INTRODUÇÃO}

O mundo está mudando; não apenas na esfera interna como também, e principalmente, na esfera internacional. Isto é verdade não só do ponto de vista político e econômico, como igualmente do ponto de vista energético. Em resposta a este novo contexto, o setor elétrico brasileiro tem modificado sua metodologia de planejamento de longo prazo ${ }^{1}$; de nosso ponto de vista, contudo, as modificações feitas são ainda tímidas.

* Professores do AIE/COPPE/UFRJ.

1 Daqui por diante, utilizaremos a palavra "planejamento" sem qualificativos em substiluição ao termo "planejamento de longo prazo".

ANÁLISE ECONÔMICA

\begin{tabular}{l|l|l|l|l} 
ANO 9 & No 15 & MARÇO/91
\end{tabular} p.121-141 
A realidade atual exige alterações mais profundas, sob pena de um crescente distanciamento entre as políticas adotadas e as exigências da realidade.

É importante aclarar que não desejamos minimizar o significativo esforço já realizado pelas empresas do Setor Elétrico Brasileiro na última década para adaptar o seu planejamento à nova realidade emergente. A utilização da metodologia de cenários, a desagregação do conşumo por setores de uso final e por região, e a apresentação a debate público dos resultados e da metodologia adotada são indicadores concretos do que já se fez. Em particular, destaque especial deve ser dado ao tratamento da questão ambiental; dentre os setores da economia com potencial de impacto sobre o meio ambiente, o setor elétrico foi o que mais passos concretos deu para incorporar essa dimensão no planejamento. No entanto, o esforço realizado nessas diversas dimensões não nos deve cegar ao fato de que os resultados até o momento se mostraram relativamente pobres se confrontados com os desafios enfrentados pelo setor.

A comparação entre o Plano 2010, publicado em 1987, o recémpublicado Plano Decenal, é iluminadora a esse respeito. Pelo ângulo da demanda, para o ano 2000 o Plano 2010 prevê um consumo total de 423,7 TWh; já o Plano Decenal reduziu essa previsão para 364,3 TWh (uma redução de cerca de 14\%). Essa redução significa a economia de $13,56 \mathrm{GW}$ instalados nos próximos dez anos, portanto aproximadamente 27 bilhōes de dólares poderão ser economizados na décàda.

Também pelo ângulo da oferta as modificações são importantes: $1625 \mathrm{MW}$ termoelétricos - de produtores independentes ${ }^{2}-$ foram acrescentados no plano decenal deslocando pelo menos capacidade hidrelétrica semelhante. Mais 3 bilhões de dólares de investimentos serão com isso economizados pelo Setor Elétrico ${ }^{3}$. Este número é conservador, pois limita-se à geração termoelétrica vinculada ao acordo do Gás Brasil-Bolívia e ao uso dos óleos ultraviscosos nas refinarias da Petrobrás. É razoável imaginar que a geração independente e privada será significativamente maior caso condiçōes institucionais adequadas venham a ser implementadas. Neste caso, aquela economia seria superior para o setor elétrico e mais ainda para o setor público.

2 Săo considerados produtores independentes empresas não-concessionárias que geram eletricidade para alimentar a rede interconectada.

3 É importante notar que a economia para o setor público será menor, posto que parte dessa capacidade resultará de investimentos do setor petróleo. 
O resultado global dessas revisões foi um deslocamento no cronograma das usinas anteriormente programadas de cerca de 3 anos em média. Dadas as condiçōes do setor público brasileiro, este resultado representa economia de investimento que está longe de ser desprezivel. Esses números permitem duas conclusões. A primeira é de que modificações na demanda (por causas essencialmente macroeconômicas) mais ajustes de oferta levaram a uma redução das necessidades de investimento das empresas do setor elétrico de cerca de 30 bilhões de dólares na década ${ }^{4}$. A segunda é que a própria dimensão desse número alerta para as margens de erro existentes neste planejamento, e para a necessidade de incorporar essa incerteza de modo diverso do que tem sido feito até o momento. Este trabalho procura discutir essas questões. $\mathrm{Na}$ primeira parte, analisamos as profundas modificações do contexto do setor elétrico, tanto nos países desenvolvidos quanto no Brasil. Estas radicais modificações de contexto exigem modificações nas estruturas do setor, bem como nas suas metodologias de planejamento. $\mathrm{Na}$ segunda parte, analisamos alguns aspectos metodológicos que necessitam ser revistos para adequar o planejamento do setor elétrico ao novo contexto. Cumpre salientar que sabemos ser difícil dissociar as modificações estruturais das metodológicas; se assim o fazemos; isso se deve sobretudo ao espaço disponivel para este artigo.

\section{O NOVO CONTEXTO DO SETOR ELÉTRICO}

Pouco a pouco, um novo consenso está emergindo entre os analistas energéticos: no final da década de 70 , a trajetória do setor elétrico em todo o mundo passou por um ponto de inflexão. Da década de 50 ao final da década de 70, o setor elétrico viveu um longo periodo de progresso que é por muitos considerado seu periodo áureo (OTA, 1985). Este periodo se caracterizou por um circulo virtuoso no qual ocorreram diversas inovações tecnológicas que reduziram substancialmente custos; as interconexões de sistemas elétricos isolados permitia reduzir a capacidade instalada por kWh gerado; o consumo de eletricidade crescia a taxas elevadas e sustentadas; foram obtidas significativas economias de escala e as taxas de juros com que o setor elétrico se financiava eram relativamente baixas. Estas condições permitiram à oferta de energia crescer rapidamente a custos decrescentes.

4 Esta redução é particularmente importante por seus efeitos de curto prazo, tanto sobre o financiamento do setor elétrico quanto sobre as contas do setor público. 


\subsection{Contexto dos Paises Desenvolvidos}

Nos países desenvolvidos, os primeiros sinais de mudança ocorreram no início da década de 70 quando o brutal aumento do preço do petróleo provocou, pela primeira vez depois de três décadas, um incremento nos custos da eletricidade gerada em usinas termoelétricas. As conseqüências da crise do petróleo não foram percebidas imediatamente pelo setor elétrico destes países; as previsões da demanda de eletricidade seguiram as tendências do consumo passado e acabaram sobreestimando fortemente o consumo real (IEA, 1985). Como os planos de construção de centrais foram baseados nessas demandas otimistas, em pouco tempo emergiram substanciais capacidades ociosas no setor elétrico, as quais aumentaram ainda mais os custos de geração.

$\mathrm{Na}$ década de 80 , os preços dos combustíveis fósseis reduziram-se significativamente, diminuindo as pressões de custo. Contudo, novas pressões de custo emergiram. Primeiro, o crescimento da taxa de juros; num setor capital-intensivo como este, aumentou fortemente o custo da dívida dos investimentos passados. Segundo, tecnologias de larga escala que prometiam grandes reduçōes de custo, como a nuclear, enfrentaram a resistência do público e custos crescentes, oferecendo os primeiros sinais de que as economias de escala no setor elétrico se estavam exaurindo (Williams \& Larson, 1989). Terceiro, a questão ambiental começou a emergir e a tornar-se importante elemento de política energética; inicialmente o problema foi percebido como local (particularmente no caso das usinas nucleares), porém rapidamente a questão ambiental transformou-se em problema regional (chuvas ácidas) e vem-se progressivamente globalizando (efeito estufa).

A pressão de custos crescentes induziu ao crescimento das tarifas elétricas e gerou incentivos à conservação de energia. Estes incentivos foram reforçados por importantes mudanças tecnológicas, particularmente na área de microeletrônica (monitoração e controle), que reforçaram os estímulos de preços (Walker, 1985, 1986) . $^{5}$ A pressão de custos e tarifas foi também responsável, nos países desenvolvidos, pela mudança na percepção dos consumidores quanto ao papel do setor elétrico. Crescente insatisfação com o custo do serviço prestado emergiu entre os consumidores, tanto residenciais quanto industriais, que se senti-

5 Por outro lado, a automação induziu à eletrificação. 
ram cativos de um monopólio que Ihes cobrava tarifas crescentes pelo mesmo serviço.

Finalmente, mas não menos importante, na década de 80 emergiu uma nova forma de filosofia política que tem sido chamada neoliberal. Esta nova filosofia teve seus primeiros impactos nos paises de lingua inglesa, porém sua influência é crescente tanto nos paises desenvolvidos quanto nos paises em desenvolvimento. O seu impacto sobre o setor elétrico se fez sentir através de forte crítica ao comportamento das empresas públicas. Esta crítica comporta dois aspectos fundamentais: a tendência dos governos em interferir no gerenciamento das empresas públicas, e a falta de claras definições dos objetivos clessas empresas o que deixa aos administradores liberdade para decidir sem qualquer controle público (Churchil \& Saunders, 1989). Mesmo nos casos em que o setor elétrico está majoritariamente em mãos privadas (caso americano), a crítica neoliberal se fez presente apontando as falhas do sistema de regulação definido e implementado pelo setor público.

A combinação de todos estes fatores gerou um meio ambiente radicalmente novo. A posição das concessionárias de energia elétrica foi enfraquecida pelo novo contexto, que ofereceu oportunidades para a emergência de novos atores no setor elétrico. Os grandes consumidores industriais, particularmente, passaram a ter muito mais influência no processo decisório. A fraqueza das concessionárias refletia em grande medida suas próprias limitaçōes. Primeiro, seus sucessivos erros na previsão de demanda provocou excesso de capacidade de oferta, conseqüentemente aprofundando a crise financeira do setor e produzindo a elevação dos seus custos. Segundo, sua dificuldade em responder de modo coerente à crescente preocupação das populações com o meio ambiente gerou insegurança quanto à sua capacidade de prestar um serviço público. Terceiro, seu conservadorismo tecnológico as impedia de avaliar corretamente o novo conjunto de tecnologias de pequeno porte (ciclo combinado, por exemplo) que emergiam, fruto do novo patamar das taxas de juros e dos limites das economias de escala. Finalmente, a acomodação à situação conquistada retardou a reflexão sobre as reformas institucionais necessárias para responder às críticas, algumas delas pertinentes, dos neoliberais ao funcionamento do setor elétrico monopolizado e estatal (Chesshire, 1989). Esta situação de fraqueza das concessionárias de energia elétrica explica, em larga medida, a facilidade que os governos neoliberais vêm encontrando para introduzir radi- 
cais modificações institucionais no setor elétrico de vários paises do mundo desenvolvido.

\subsection{O Contexto Brasileiro}

Até a crise do petróleo, as tendências do setor elétrico no Brasil eram muito similares às dos paises desenvolvidos, ainda que o meio ambiente em que as concessionárias brasileiras operavam fosse bastante distinto. O setor elétrico era capaz de atender uma demanda que crescia celeremente (em alguns anos a taxas superiores a 10\%), a tarifas decrescentes em termos reais. Apesar da performance tecnológica das concessionárias ser inferior quando comparada com a dos países desenvolvidos, a difusão de novas tecnologias provenientes daqueles países permitia obter substanciais ganhos de produtividade no setor elétrico, reduzindo custos e tarifas reais.

Como nos paises desenvolvidos, o contexto do setor elétrico dos países em desenvolvimento modificou-se radicalmente desde então $(0$ liveira \& MacKerron, 1990), inclusive no Brasil. Contudo, tanto as concessionárias quanto os consumidores tardaram em dar-se conta da nova situação. A singular dominância da geração hidroelétrica no parque gerador brasileiro permitiu isolar o setor dos incrementos de custo derivados do aumento de preços dos combustiveis fósseis; além disso, subsistiam algumas oportunidades para incrementar o desempenho tecnológico do setor elétrico brasileiro, como por exemplo a integração de novas áreas geográficas no sistema interconectado, com potencial para reduzir custos. Estes elementos não eram, porém, suficientes para impedir o crescimento do custo da eletricidade no Brasil; as forças que geravam aumentos de custos nos países desenvolvidos também agiam no Brasil.

A queda no ritmo de crescimento da demanda devida à recessão dos inícios dos 80 , por exemplo, só foi possivel postergar com a criação de tarifas fortemente reduzidas (um sexto da tarifa normal) para induzir o consumo de eletricidade industrial. Os custos de investimento e de rolagem da dívida das concessionárias eram crescentes devido às elevadas taxas de juros. Também as reticências da opinião pública à construção de grandes barragens hidroelétricas tornavam mais dificil e mais cara a construção de novas centrais. Apesar dessa dinâmica de custos crescentes, as tarifas não cresceram; de fato, elas foram reduzidas (Figura 1). Sucessivos governos preferiram proteger os consumidores do impacto de curto prazo de tarifas crescentes, invocando razóes macroe- 
conômicas para tanto. Nestas circunstâncias, subsidios teriam que ser oferecidos ao setor elétrico para cobrir seus custos adicionais, o que infelizmente não só não ocorreu como os investimentos das concessionárias seguiram um ritmo "stop and go", ora cortados ora retomados em nivel mais elevado para atender uma demanda que seguia crescendo fortemente. Fazendo face a uma redução nos recursos próprios à sua disposição, as empresas públicas do setor foram induzidas a se endividarem fortemente (num periodo de taxas de juros flutuantes e crescentes) para financiar seus investimentos.

Essa dinâmica desestruturou a situação financeira do setor elétrico brasileiro. A remuneração dos seus ativos caiu muito abaixo da remuneração legal, reduzindo-se a sua capacidade de autofinanciamento. Ao pobre desempenho econômico do setor, somou-se a deterioração das contas externas do País para, efetivamente, eliminar dos planos de expansão do setor a capacidade de mobilizar financiamentos. Recuperar a capacidade de financiamento é hoje a principal prioridade do setor elétrico brasileiro (Araújo, 1990). Esta prioridade não pode, contudo, ser perseguida fora do contexto da dinâmica de inovações tecnológicas que vem ocorrendo nos paises desenvolvidos. Ela não pode, tampouco, negligenciar a necessidade de uma profunda revisão na estrutura institucional do setor elétrico brasileiro, particularmente na sua estrutura de regulação das atividades das concessionárias.

\section{METODOLOGIA ATUAL: LIMITES E IMPLICAÇÕES PARA O PLANEJAMENTO}

Dada a estrutura institucional do setor, a holding Eletrobrás coordena os estudos de planejamento através do Grupo Coordenador do Planejamento dos Sistemas Elétricos (GCPS) - com representantes das empresas federais e associadas. O Plano 2010 e o Plano Decenal 19901999 explicitam o reforço desse grupo, como um mecanismo de compatibilização entre a holding e as subsidiárias. Outros objetivos enfatizados são o de tornar o planejarnento do setor uma atividade cada vez mais aberta à participação da sociedade, e o de enfrentar as incertezas através de cenários, análise de sensibilidade e mecanismos de revisão (Eletrobrás, 1987, 1990). A metodologia adotada e os resultados obtidos têm sido regularmente publicados em documentos públicos. 
Não pretendemos cobrir toda a gama do planejamento, mas limitar-nos a três aspectos: a previsão de mercado, incluindo o tratamento da incerteza; o problema da eficiência; e o papel das restriçöes financeiras. Se não tratarmos do aspecto ambiental, isto é um reconhecimento dos avanços realizados pelo setor para incorporar essa dimensão em sua metodologia de planejamento, embora muito exista ainda a fazer nessa direção. É preciso reconhecer que nenhum setor produtivo está hoje tảo aberto ao exame crítico e ao debate público como o elétrico, atràvés da publicação de sua metodologia de planejamento, com hipóteses e resultados, e da realização de audiências públicas em projetos importantes. É plausivel que as características institucionais do setor tenham contribuido neste sentido: as funções centrais do DNAEE e da ELETROBRÁS, opostas e equilibradas por concessionárias importantes, certamente ajudaram.

Hoje, o planejamento do setor elétrico tem uma lógica seqüencial: inicia-se com uma projeção da demanda, que é utilizada como referência para programar a expansão da capacidade de geração, transmissão. e distribuição; a esta altura são introduzidas as restrições financeiras, que servem para rever o programa de obras; o resultado final é o programa consolidado de investimentos. Ênfase especial é dada a estudos sobre o risco de racionamento e interrupção, existindo ainda certa preocupação quanto à transferênicia de tecnologia (Eletrobrás, 1990).

Esta lógica contém a hipótese implícita de que a demanda é um dado exógeno e cabe às concessionárias atendê-la em sua plenitude, respondendo ao preceito legal de que as concessionárias são responsáveis pela garantia do suprimento. Ela mostrou-se adequada ao contexto vigente até a década dos setenta, caracterizado por um ambiente favorável ao financiamento da expansão do sistema, e um projeto de desenvolvimento baseado no Estado e na centralização. Nenhum desses supostos é hoje evidente. Dada a importância da previsão de mercado na metodologia de planejamento existente, convém dedicar a ela maior espaço.

Neste aspecto, o setor apresentou um salto qualitativo no Plano 2010, ao trabalhar em nivel mais desagregado. O comportamento de nove categorias de consumo foi estudado, analisando-se à parte as grandes cargas; a análise foi conduzida em diferentes niveis de profundidade, conforme o segmento de consumo, e levou em conta a existência de projetos industriais relevantes para calibrar as previsões de curto 
e médios prazos. $O$ procedimento não usou metodologia de usos finais ${ }^{6}$ de modo explícito, mas aproximou-se bastante; projeções econométricas foram usadas apenas para complementar a análise. Neste ponto, cabe observar que o método não foi utilizado em toda sua potencialidade. Duas observações justificam nossa crítica: a primeira, quanto às implicações dos resultados obtidos - o Plano 2010 implica uma reversão do processo de eletrificação da economia, em contradição com o que vem ocorrendo no Brasil e em todas as economias industriais (essa inconsistência foi em parte reduzida pelo Plano Decenal); isto tem implicaçōes importantes para o curto e médio prazos. Em segundo lugar, apenas uma previsão de referência foi retida para o longo prazo - perdendo assim grande parte do poder do método, embora cenários alternativos tenham sido elaborados para o curto e o médio prazos. Analisemos estes dois pontos.

No Plano 2010, as hipóteses adotadas implicam um leve crescimento do conteúdo elétrico do PIB (eletricidade consumida por unidade do PIB) de 762 Wh/US\$ (de 1985) em 1985 para 776 em 1990 e 783 em 1995, caindo novamente para 769 em 2000 e 740 em 2010 (Araújo, 1990); estes resultados são obtidos antes mesmo de levar em conta políticas de conservação (as metas do PROCEL são utilizadas apenas posteriormente, na definição dos planos de expansão da capacidade). Estes números equivalem a uma freada e a uma reversão da eletrificação observada no passado, sem política explícita de conservação (ver Figura 2). O Plano Decenal revê hipóteses e explicita melhor a metodologia utilizada para as novas projeções. As principais diferenças metodológicas com o Plano 2010 são que os efeitos da política de conservação são considerados nas previsōes do Plano Decenal, de um lado; por outro, este último omite a autoprodução, levada em conta no plano anterior. Seria, portanto, de se esperar que os conteúdos energéticos ficassem abaixo dos índices obtidos pelo Plano 2010.

Entretanto, a análise dos resultados do Plano Decenal mostra números cerca de $5 \%$ mais elevados: os conteúdos elétricos do PIB previstos para 90,95 e 2000 são respectivamente de 803,830 e 807 Wh/US\$

6 A metodologia de usos finais vincula a demanda de energia ao serviço prestado pelos equipamentos que consomem energia. Esta metodologia emergiu nas década dos setenta e impós-se como método superior para a prospectiva energética e análise de demanda. Ver Energia e Desenvolvimento: que desafios? quais métodos?. 
$(1985)^{7}$. Esta discrepância deve-se essencialmente ao fato do Plano Decenal incorporar o aumento de conteúdo ocorrido nos últimos três anos, devido à recessão (Araújo, 1990a). É interessante notar que entre 90 e 2000 os conteúdos permanecem aproximadamente estáveis, à semelhança do Plano 2010. Este resultado deriva diretamente da hipótese de que não prosseguirá a penetração da eletricidade, por saturação dos segmentos de consumo, e que políticas de conservação cobrirão a eletrificação residual. No entanto, existem sinais claros de forte tendência à difusão de equipamentos eletrointensivos, que teria especial papel numa recuperação (JWCA, 1989). Este efeito de longo prazo, combinado com a inércia de curto prazo, tornaria plausível um aumento do conteúdo - mormente se a recessão prolongar-se. Por outro lado, o grau de inércia efetivamente existente no mercado impede que essas politicas venham a ter pleno impacto no curto e médio prazo.

As causas principais dessa inércia são a rigidez do parque de equipamentos, que não pode ser reconvertido da noite para o dia, e que de fato aumenta mesmo numa recessão; condições financeiras em geral (e mormente agora) desfavoráveis ao sucateamento acelerado de equipamentos para substituí-los por novos; e conservadorismo dos hábitos, por razões diversas. Na recuperação, embora vários desses fatores percam força, a penetração de equipamentos elétricos - introduzidos pela automação, na indústria, e pelo efeito-renda nos demais setores, tende a elevar sensivelmente o conteúdo. Na ausência de uma política consistente de conservação, não é de se esperar pois uma inflexão significativa em relação ao comportamento recente; uma análise dinâmica desse comportamento (Araújo, 1990a) revela uma elasticidade-produto de longo prazo da ordem de 1,5 e um coeficiente de inércia de 0,9 (isto é, o impacto de alterações contextuais no primeiro ano é apenas $10 \%$ de seu impacto total).

Os resultados do Plano Decenal parecem mostrar, assim, uma significativa eficácia das Políticas de Conservação, embora o espaço que o documento Ihes concede seja praticamente zero. Para comparação, as figuras 2 e 3 mostram os resultados dos Planos junto com a evolução (projetada econometricamente) do consumo para duas hipóteses de evolução do PIB: recuperação após 1991 (com 6\% a.a. entre 93

7 Para comparação com o Plano 2010, convém lembrar que as séries de consumo passado não sáo consistentes entre os planos - o Plano Decenal exclui a autoprodução. Como a geraçāo dessa categoria é suposta quase constante no Plano 2010, e sua dimensăo é pequena, a distorção não chega a ser séria. 
e 95, caindo progressivamente para $5 \%$ a.a. pelo ano 2000 ) ou estagnação no restante da década (com crescimento líquido zero entre 1990 e 1995).

Pode observar-se que, em qualquer caso, crescerá o consumo de eletricidade nos próximos dez anos; mesmo no cenário de estagnação haverá crescimento de cerca de $20 \%$ até 1995 , e no de recuperação ao redor de $30 \%$ no mesmo periodo, devido à inércia (o efeito das hipóteses de crescimento se faz sentir mais fortemente ao final da década). A figura 2 enfatiza, por outro lado, o impacto da recessão sobre o conteúdo elétrico - aumenta o patamar, deslocando para cima a curva Eletricidade $x$ PIB. A prazo mais longo, no entanto, a elasticidade-produto de longo prazo domina; e seu valor elevado indica uma tendência ao aumento do conteúdo, na ausência de uma política de conservação. É preciso contudo relativizar esses resultados, pois essa elasticidade elevada decorre em parte de fatores específicos ao período - tarifas declinantes e implantação de indústrias pesadas - que não deverão repetir-se no futuro. Neste sentido, a projeção "alta" está superestimando o consumo. É ainda digno de nota que as projeções de consumo do Plano Decenal (Figura 3) aproximam-se bastante da projeção econométrica "alta", por uma combinação de conteúdos mais baixos e ritmo de crescimento mais elevado para o PIB.

A ausência de uma separação nítida entre os impactos de açōes de Política de Conservação e do contexto macroeconômico na evolução do mercado ressalta duas deficiências da atual metodologia de previsão, ambas desperdiçando o potencial do método de usos finais e do método de cenários: a primeira, que já discutimos, é a desconsideração de fatores de eletrificação ligados ao efeito-renda e à difusão de novas tecnologias centradas no uso da eletricidade, bem como do tratamento de políticas de conservação como um instrumento de ação, ao mesmo título que o Programa de Obras.

A segunda é o tratamento da incerteza, que passamos a discutir. A homenagem prestada ao "método de cenários" por ambos os Planos não tem um resultado concreto: ao contrário, após discussões sobre fatores de incerteza aqueles recaem num único cenário e numa única politica. Desta maneira, a verdadeira contribuição dos métodos de cenários é esquecida: a possibilidade de analisar de modo sistemático alternativas e contingências, de modo a construir uma estratégia flexivel e robusta. Para sermos justos, cumpre admitir que o setor elétrico brasileiro não está só neste esquecimento: são raras as organizações que usam 
corretamente as técnicas de cenários, e mais raras ainda as que publicam seus estudos ${ }^{8}$. No entanto, o tratamento dado à incerteza por ambos Planos implica dar à previsão um caráter quase deterministico; esta atitude poderia ser justificada em circunstâncias de baixo risco, mas este não é, de modo algum, o caso. É bem verdade que são acrescentados ao Plano elementos de flexibilização, num reconhecimento das incertezas presentes; mas, na ausência de uma estruturação das mesmas, pode-se questionar se a flexibilidade assim obtida é adequada.

Um segundo aspecto a discutir é o tema da eficiência.

A eficiência no setor elétrico tem muitas acepções e cobre muitos aspectos: a eficiência no uso é a mais comumente referida, e aquela que normalmente se subentende ao se falar de conservação. Mas vimos acima outro aspecto - a ineficiência gerada por uma recessão, que tem a ver basicamente com o crescimento vegetativo do parque de equipamentos. Ambos aspectos têm de comum entre si (e com a tendência à eletrificação) o fato de se referirem à demanda, e responderem a açōes sobre ela. É digno de nota o fato de tais ações não estarem integradas orgânicamente ao planejamento do setor.

Mas outras acepçōes de eficiência têm implicações distintas; assim, a "administração de cargas" busca reduzir as variações horárias e sazonais da carga do sistema, de modo a melhorar a eficiência deste último. Isto permite reduzir a demanda de ponta e, conseqüentemente, os investimentos necessários para supri-la. Embora normalmente se aja sobre a demanda (através de tarifas horo-sazonais e contratos especiais para grandes cargas) para atingir aquele objetivo, é possivel melhorar o fator de carga do sistema ${ }^{9}$ através de ações sobre a oferta. Por exemplo, utilizar de modo mais pleno a capacidade de co-geração do setor sucro-alcooleiro (pelo menos no Sudeste) acrescentaria de 2 a 3 GW durante a estação seca; isto permitiria usar melhor hidrelétricas convencionais, aumentando a disponibilidade de água. Este valor é conservador, por não levar em conta o potencial de co-geração em diversos outros setores industriais; uma política agressiva de co-geração poderia reduzir em mais alguns gigawatts as necessidades de investimento das concessionárias. É preciso ressaltar, contudo, que isto requer a solução de vários impedimentos, o principal dos quais é a diferença de pontos

8 Uma notável exceção pode ser vista em (Southern California Edison, 1989).

9 Definido como a razão entre a energia média utilizada e a energia máxima que o sistema pode fornecer. 
de vista entre o setor elétrico e os co-geradores em prospectiva, que se concretiza no debate sobre tarifas e condições contratuais.

Por outro lado, o sistema elétrico brasileiro apresenta perdas de transmissão e distribuição relativamente elevadas; isto decorre em parte das longas linhas de transmissão, que totalizam cerca de 130 mil quilômetros; mas também de grande incidência de ligaçōes clandestinas, que aparecem como perdas de distribuição. Uma estimativa dessa importância está na discrepância entre dados do IBGE e da Eletrobrás sobre a taxa de eletrificação das residências, com cerca de 20 pontos percentuais a mais nas pesquisas do IBGE. Adicionalmente, o desempenho do sistema foi prejudicado pelos problemas financeiros setoriais, com o adiantamento ou cancelamento de investimentos necessários e menor manutenção.

Finalmente, deve-se considerar a eficiência econômico-financeira das empresas do setor; as ações aqui prendem-se em parte ao aumento das receita, e principalmente à redução de custos. Quanto ao primeiro, caberia resolver o problema das ligações clandestinas, bem como equacionar o problema do atraso no pagamento por parte de grandes consumidores industriais, e eliminar tarifas subsidiadas para indústrias eletrointensivas como a do alumínio. Quanto à redução de custos, nas atuais circunstâncias, este é um tema de importância crucial para o setor - mas há obstáculos importantes a enfrentar. o oligopólio de fornecedores de equipamentos e de firmas de engenharia é talvez o mais difícil de resolver, embora outros existam (o próprio grau de endividamento do setor limita bastante o espaço das açōes). Importa, no entanto, enfrentar esse problema, que tem levado com freqüência a custos de construção muito superiores aos projetados. Caso o planejamento do setor não incluia essas ações entre suas prioridades, a própria política de nacionalização de equipamentos e de desenvolvimento tecnológico perseguida desde a criação da Eletrobrás (Araújo, 1990) ficará comprometida pelas dificuldades financeiras.

Porém as maiores dificuldades metodológicas estão ligadas ao contexto econômico-financeiro em que o planejamento está sendo feito; a seqüência de planejamento seguida pelo setor pressupõe implicitamente que as restriçōes financeiras são de natureza secundária, podendo afetar o calendário de obras e o nivel de risco de não-atendimento, mas deixando intactas as opções básicas e a estrutura do setor. Ocorre que, conforme vimos na seção anterior, estes pressupostos não mais são válidos. Muito pelo contrário, essas restrições são as mais premen- 
tes que o planejamento do setor deve enfrentar nos próximos anos e colocam em questão a sua própria estrutura institucional. Nestas condições, o esquema de planejamento precisa ser modificado. Se as restrições são muito grandes, as modificações induzidas no programa de obras deixam de ser marginais, invalidando a segunda etapa da sequeência de planejamento - é, pois, preciso colocar essas restrições no início do processo.

No que se refere a essas restrições, dois pontos devem ser notados. Primeiro, não se deve confundir restrição com um patamar rígido; objetivamente, estas restriçōes se colocam em termos de niveis máximos e mínimos de investimento. Deverá haver negociação, buscando o setor encontrar o financiamento necessário ao seu plano de expansão, dentro da faixa de investimentos fixadas pelo governo. Segundo, há uma diferença fundamental com respeito à situação anterior: não se pode presumir a priori que a demanda de eletricidade virá a ser integralmente atendida pela expansão de capacidade das concessionárias. $O$ setor elétrico deve incorporar a seu processo de planejamento a expansão da autoprodução e da produção independente, agregando capacidade de oferta à expansão planejada pelas concessionárias. Por outro lado, isto exige a incorporação de uma Política de Demanda ao planejamento do setor. Uma implicação disto é que a lógica do planejamento não pode mais ser seqüencial: o mercado não é mais um dado exógeno.

Dadas estas limitações, parece-nos que a metodologia de planejamento do setor adequada às novas circunstâncias deve ter uma lógica distinta. O planejamento iniciar-se-ia com a consideração paralela do contexto macroeconômico, com suas implicaçōes sobre a dinâmica do mercado e sobre as condições de financiamento, e das restrições financeiras colocadas pelo Programa de Governo. Previsões de demanda teriam de ser feitas setorialmente e diferenciadamente, segundo disponibilidades de financiamento do Estado e de setores privados. Alternativas de expansão conjugando ação das concessionárias, dos autoprodutores e dos produtores independentes seriam então analisadas, distinguindo entre as ações que o Estado executará e as que ficarão a cargo do setor privado. Partindo dessa análise, diferentes cenários seriam gerados correspondendo aos diversos contextos, com políticas adequadas a cada um.

Uma vez feita essa análise, é possivel definir um cenário de referência e uma política robusta e flexivel, a ser apresentados à sociedade; um subproduto do estudo de cenários é a identificação de indicadores a 
monitorar e planos de contingência. Finalmente, mecanismos de estímulo à eficiência devem ser implantados como parte integrante do processo de planejamento e operação, a fim de garantir a viabilidade de longo prazo das políticas.

\section{CONCLUSÕES}

O planejamento do setor elétrico não tem mostrado eficácia na resposta aos desafios gerados pela profunda mudança do contexto econômico-social e energético a partir dos anos 70 . Esta perda de eficácia não se deve a uma insuficiência intrinseca do instrumental de planejamento, que se mostrou adequado por mais de trinta anos. As profundas modificações ocorridas em nível internacional e doméstico invalidaram as hipóteses sobre as quais foi construído esse instrumental. As conseqüências dessa inadequação têm custado muito à sociedade brasileira. Investimentos têm sido antecipados relativamente às reais necessidades de expansão do sistema para atender a demanda; com isto, deteriorou-se ainda mais a já difícil situação financeira do setor elétrico. Por sua vez, esta deterioração força a postergação de investimentos necessários na fase seguinte, gerando riscos de racionamento. Esse circulo vicioso é extremamente nocivo à saúde financeira do setor, colocando em risco a continuidade do abastecimento elétrico da economia brasileira.

Um novo instrumental faz-se necessário, ou melhor: o processo de planejamento deve ser modificado, e o instrumental ajustado a esse novo processo. Estas modificações deveriam atender às duas limitações básicas do atual processo: a incapacidade de tratar adequadamente 0 problema das incertezas e a inflexibilidade no tratamento das restriçōes financeiras.

O tratamento das incertezas é falho em dois pontos principais: na previsão de demanda e na utilização do método de cenários. A demanda é vista como um dado exógeno e ações sobre a demanda são limitadas a um papel secundário, não sendo integradas ao cerne do processo de planejamento; esta visão impede o aproveitamento pleno da análise desagregada por mercados que é atualmente conduzida. Por outro lado, o método de cenários, tampouco, é utilizado corretamente: ele deveria levar a análises de contingências para identificar graus de liberdade e elaborar uma estratégia robusta e flexivel. No entanto, essas análi- 
ses não fazem parte dos estudos, que se limitam a uma projeção de referência - sobre a qual se constrói o programa de obras.

A inflexibilidade do processo atual quanto às restrições financeiras subestima a importância destas no novo contexto, implicitamente supondo que será possivel satisfazê-las sem abrir mão da hipótese de que a demanda de energia elétrica será integralmente atendida pelas concessionárias. O setor passa por uma crise financeira sem precedentes e da qual não parece haver saída fácil nem rápida - tanto mais que os custos tendem a ser crescentes daqui por diante. O papel do Estado é hoje alvo de questionamento.

O esquema de planejamento deve ser modificado de modo a ter em conta as restrições de financiamento estatal e a orientá-lo para busca da eficiência. Nesse processo, algumas noções são fundamentais: primeira, que as restrições devem ser colocadas em termos de niveis máximos e mínimos de investimento, abrindo-se espaço para negociação do nivel adequado. Segunda, que o financiamento dos investimentos não se restringe à potencialidade de mobilização de recursos das concessionárias. Terceira, o mercado não é mais um dado exógeno, sendo preciso incorporar uma política de demanda ao planejamento do setor. Quarta, que é preciso reduzir custos de investimentos e elevar a receita eliminando tarifas subsidiadas e inadimplências.

Em sintese, a metodologia de planejamento do setor deve ter uma lógica distinta. As previsões de demanda devem ser feitas setorialmente e diferencialmente, segundo disponibilidades de financiamento do Estado e de setores privados. As alternativas de expansão por parte das concessionárias e dos produtores devem ser avaliadas.

Desta forma, é possivel definir uma política robusta e flexivel, tendo como um subproduto dos cenários um conjunto de indicadores que permite monitorar políticas adotadas e traçar planos de contingência. 


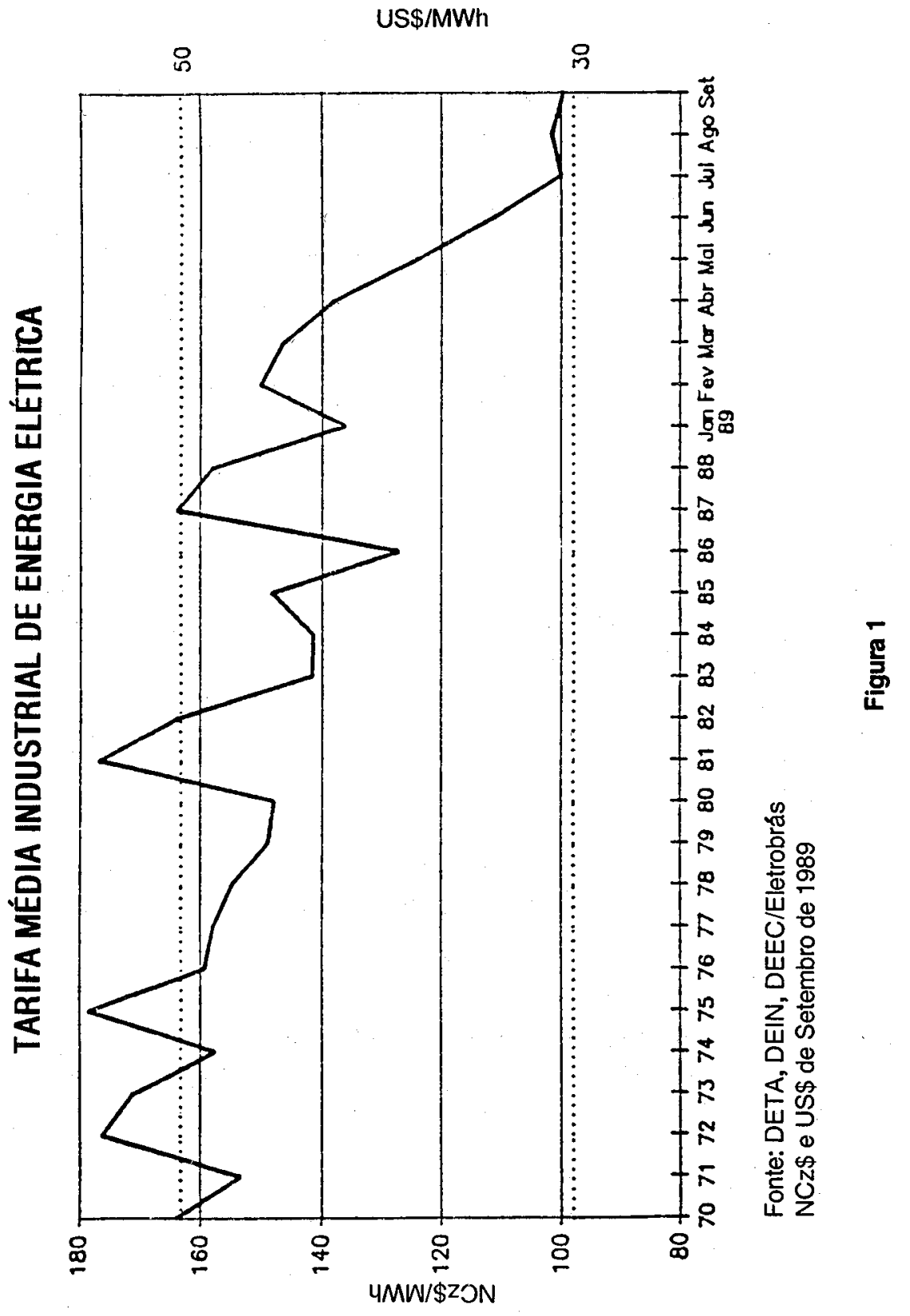




\section{CONTEÚDO ELÉTRICO DO PIB OBSERVAÇÕES E PROJEÇÕES}

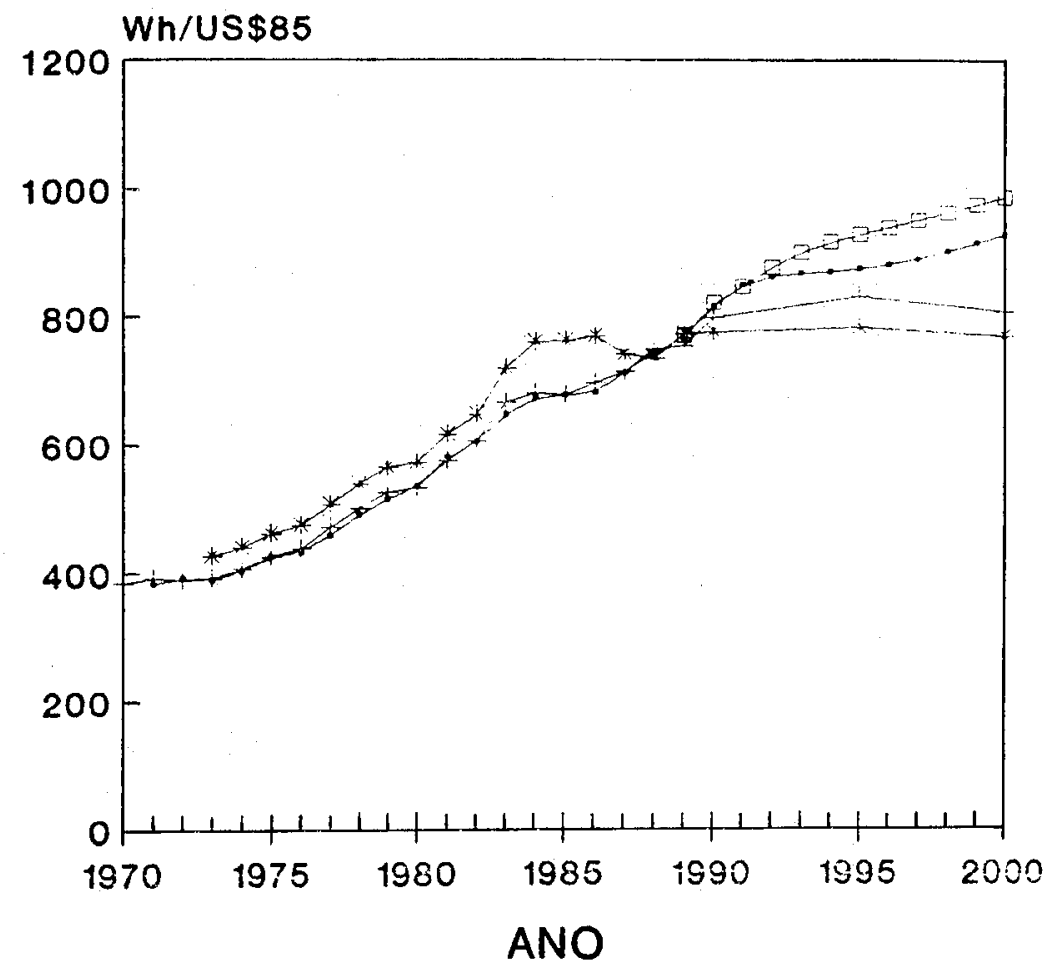

$\begin{array}{ll}\rightarrow \text { Reg.DInamica (cresc) } & + \text { Plano Decenal } \\ \text { *- P̌lano } 2010 & \square-\text { Reg.Dinamica (estag) }\end{array}$

Figura 2 


\section{CONSUMO DE ELETRICIDADE OBSERVAÇÕES E PROJEÇÕES}

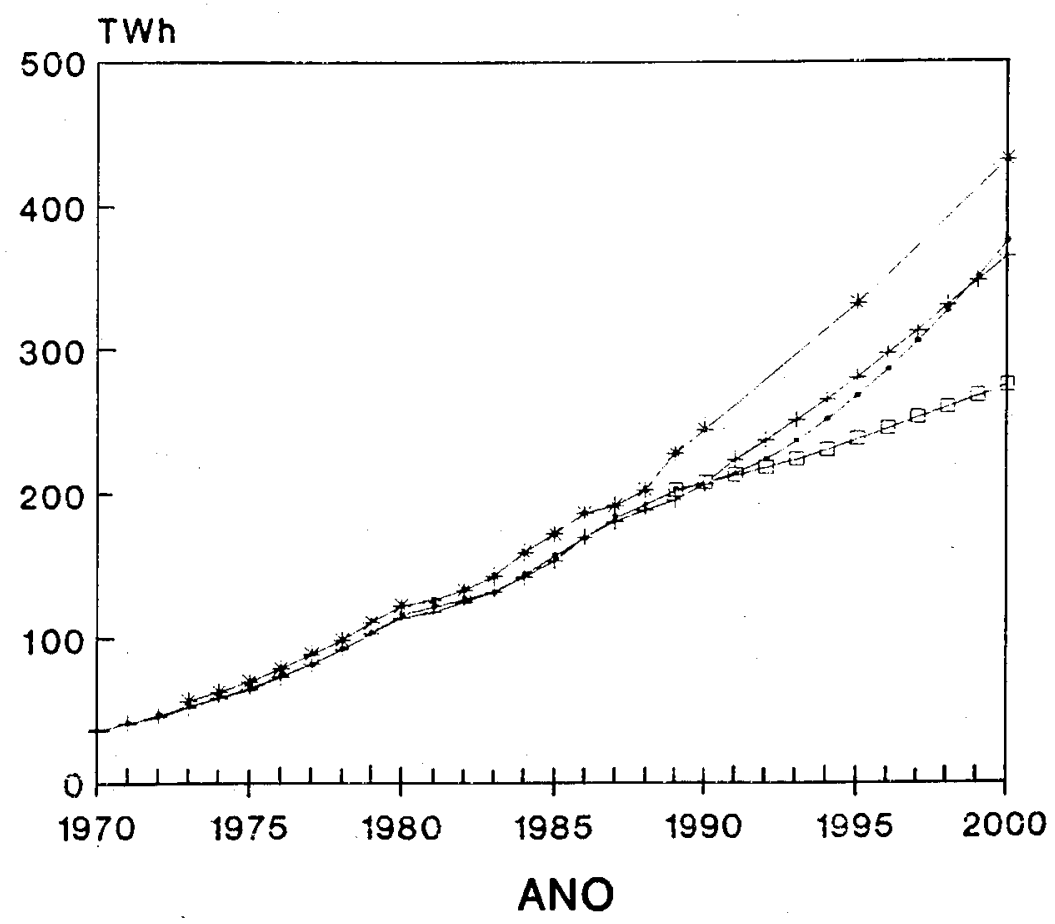

$\begin{array}{ll}- \text { Reg.Dinamica (cresc) } & - \text { Plano Decenal } \\ \text { * Plano } 2010 & \rightarrow \text { Reg.Dinamica (estag) }\end{array}$

Figura 3 


\section{BIBLIOGRAFIA}

ARAÚJO, J.L. Key Issues for the Brazilian Power System: Synthesis

Report. Grenoble, COPED Annaul Meeting, Apr. 1990.

Perspectivas do Consumo de Eletricidade no Curto e

Médio Prazos. Rio de Janeiro, AIE/COPPE/UFRJ, ago. 1990a.

CHESSHIRE, J. Electricity Privatisation: Proposed Structure and Unresolved Dilemmas. London, World Electricity Conference, Nov. 1989.

CHURCHILL, A.A. \& SAUNDERS, R.J. Financing of the Electricity Sector in Developing Countries. Washington, Industry and Energy Department, World Bank, 1989.

COPED. Cooperative Research Program on Energy and Development. Energy and Development: What Issues? Which Methods?, Bruxelles, 1984.

ELETROBRÁS. Plano 2010 (Relatório Geral). Brasília, 1987. Plano Decenal 1990-1999. Brasilia, 1990.

IEA. International Energy Agency. Electricity in IEA Countries: Issues and Outlook. Paris, OECD/IEA, 1985.

JWCA. Jorge Wilheim Consultores Associados. Pesquisa de Posse e Intenções de Compra de Eletrodomésticos no Estado de São Paulo, 1989.

MINISTÉRIO DE MINAS E ENERGIA. Balanço Energético Nacional 1989. Brasilia, 1989.

OLIVEIRA, A. de \& MACKERRON, G. British Privatisation of the Energy Industries, the World Bank' and Implications for Third World Countries. Surrey Energy Economics Center, Discussion Papers Series, Mar. 1990.

OTA. Office of Technology Assessment. New Electric Power Technology. Washington, DTA-E246, 1985.

SOUTHERN CALIFORNIA EDISON. Structuring the Future. Tecnological Forecasting and Social Change. Jan. 1989.

WALKER, W. Information Technology and the Use of Energy. Energy Policy, Oct. 1985.

icy. Dec. 1986 .

WLLIAMS, R.A. \& LARSON, E.D. Expanding Roles of Gas Turbines in

Power Generation. JOHNSON, J.B. et alii. Electricity: Efficient Use 
and New Generation Technologies, and their Planning Implications, Lund University Press, 1989.

\section{ABSTRACT \\ METHODOLOGICAL PLANNING FOR THE ELECTRICAL SECTOR: QUESTIONS FOR THE 90'S}

The methods of planning used by the Brazilian electric sector were formed during the 60's and 70's and they were perfectly adequate to the economic-institutional context of that time. However, the crisis of the 80's and the growth of neoliberalism thought, radically modified that context. On the other hand, increasing preoccupation with the environment and the efficient use of energy, originated new problems to the sector. Our thesis is that the deep changes that occurred in the context will require similar changes in the planning methods. In this paper we discuss the problems and the foreseeable context of the 90 's, and the necessary methodological changes that will be necessary. 